\title{
Direct Detection of Pharmaceuticals and Personal Care Products from Aqueous Samples with Thermally-Assisted Desorption Electrospray Ionization Mass Spectrometry
}

\author{
Ian S. Campbell, Alain T. Ton, Christopher C. Mulligan
}

Department of Chemistry, Illinois State University, Normal, IL 61790, USA

\begin{abstract}
An ambient mass spectrometric method based on desorption electrospray ionization (DESI) has been developed to allow rapid, direct analysis of contaminated water samples, and the technique was evaluated through analysis of a wide array of pharmaceutical and personal care product (PPCP) contaminants. Incorporating direct infusion of aqueous sample and thermal assistance into the source design has allowed low ppt detection limits for the target analytes in drinking water matrices. With this methodology, mass spectral information can be collected in less than $1 \mathrm{~min}$, consuming $\sim 100 \mu \mathrm{L}$ of total sample. Quantitative ability was also demonstrated without the use of an internal standard, yielding decent linearity and reproducibility. Initial results suggest that this source configuration is resistant to carryover effects and robust towards multicomponent samples. The rapid, continuous analysis afforded by this method offers advantages in terms of sample analysis time and throughput over traditional hyphenated mass spectrometric techniques.
\end{abstract}

Key words: Desorption electrospray ionization, Ambient mass spectrometry, Environmental monitoring, Emerging contaminants, Pharmaceuticals and personal care products (PPCP)

\section{Introduction}

$\mathrm{T}$

he accumulation of pharmaceuticals and personal care product (PPCP) contaminants in environmental systems has quickly become a major concern, as usage of this class of chemicals continues to increase in magnitude as more products become available. Characterization of these compounds in environmental samples represents a daunting task due to the breadth of chemicals this encompasses, the diversity of sample matrices that are of interest (e.g., water, sludge, soil) and the multitude of routes of entry into the

Electronic supplementary material The online version of this article (doi:10.1007/s13361-011-0144-6) contains supplementary material, which is available to authorized users.

Correspondence to: Christopher C. Mulligan; e-mail: mulligan@ilstu.edu environment $[1,2]$. Pharmaceuticals frequently undergo an incomplete metabolism in the human body, leaving the remainder to be naturally excreted and enter municipal wastewater systems [3], and unused medications are often discarded improperly. The average person uses several consumer products related to hygiene daily, and these chemicals are rinsed away during bathing and enter wastewater systems, as well.

While conventional water treatment systems are efficient at removing most contaminants, they are not designed or capable of removing all PPCPs, and these compounds and their conjugates enter potable water supplies [4]. While targeted assessments have been reported [5, 6], little is known regarding the environmental fate and potential risks of this class of chemicals as a whole. The ever-changing and persistent nature of this problem shows a need for rapid, accurate monitoring of PPCP dispersion into water supplies 
and surrounding ecosystems to help delineate all of the uncertainty [7].

Aqueous environmental sample analysis is commonly done with mass spectrometry (MS) coupled with gas (GCMS) or liquid (LC-MS) chromatographic separation, commonly employing high resolution or tandem MS analysis, as recently reviewed $[8,9]$. Hyphenated MS techniques are regarded for their performance, particularly for high quantitative ability, and while they offer many benefits, these techniques often require multiple instrumental methods to cover a broad range of analytes, suffer from long analysis times, and require extensive sample preparation [9-11].

Eliminating the sample preparation requirements for aqueous contaminant analysis is desirable, making recently-developed, ambient mass spectrometric techniques $[12,13]$ an interesting alternative to hyphenated MS methods. Ambient MS investigation of PPCPs in condensed phases or as surface-bound residues has been extensively reported, demonstrating direct sample analysis without prior preparation while exploiting the inherent advantages of MS analysis [14-20]. Direct analysis of liquids and aqueous samples has also been shown with ambient MS methods, by deposition onto a surface substrate [21] and by direct flow injection of sample into the ionization source [22-25], but can require matrix additives [26] or preconcentration to reach desired detection limits [27-29].

The preferable method for analysis of aqueous environmental contaminants would not only require little to no sample preparation and small sample volumes, but also yield low detection limits, allow broad application to various classes of chemicals, and provide quantitative data. In an effort to fulfill these requirements with a single technique, we investigate a variant of desorption electrospray ionization mass spectrometry (DESI-MS) [12], evaluating the technique through analysis of a wide array of PPCP contaminants. DESI-MS is carried out by directing charged microdroplets generated by a pneumatically-assisted electrospray of an appropriate solvent onto a sample of interest, desorbing neutral analyte as secondary ions that are detected via MS. Thermal assistance has been incorporated into the ionization source design to enhance sensitivity, while allowing direct analysis of aqueous environmental contaminants in a dynamic nature.

\section{Experimental}

\section{Ionization Source Design}

To directly analyze aqueous PPCP contaminants, the traditional DESI-MS source design was modified to incorporate direct infusion of water samples via a controlled-flow capillary delivery system, analogous to direct flow injection ESI-MS [30]. With traditional DESI-MS, the analysis point is typically a solid surface or condensed phase (i.e., glass slide, pharmaceutical tablet, fabric, skin), and liquid samples are spotted onto appropriate surfaces, dried, and analyzed. As independently reported by the research groups of Zhang
[22] and Chen [23], liquid samples can be analyzed by introduction through capillary delivery, with the end of the capillary or deposition surface serving as the DESI-MS analysis point. Two distinct source designs were examined in this investigation utilizing capillary delivery, with a ThermoScientific LCQ Fleet (Waltham, MA) quadrupole ion trap mass spectrometer used for mass analysis for all studies.

\section{Method 1. Direct Flow Injection DESI-MS}

A commercially-available DESI source (OmniSpray Source; Prosolia, Inc., Indianapolis, IN, USA) was used as the foundation for all ionization source designs. The Omni Spray source consists of $x-y-z$ positioners that allow movement of both the sample platform and electrospray emitter and $\mathrm{CCD}$ cameras, allowing flexibility, precision, and accuracy in positioning. A tangent arm rotary stage allows precise angular adjustment of the electrospray emitter from 0 to $90^{\circ}$. To allow direct flow injection, referred to as Method 1 (Figure 1a), a fused-silica capillary (i.d. $100 \mu \mathrm{m}$, o.d. $150 \mu \mathrm{m}$; Agilent Technologies, Santa Clara, CA, USA) was used to infuse aqueous samples from a Gastight syringe
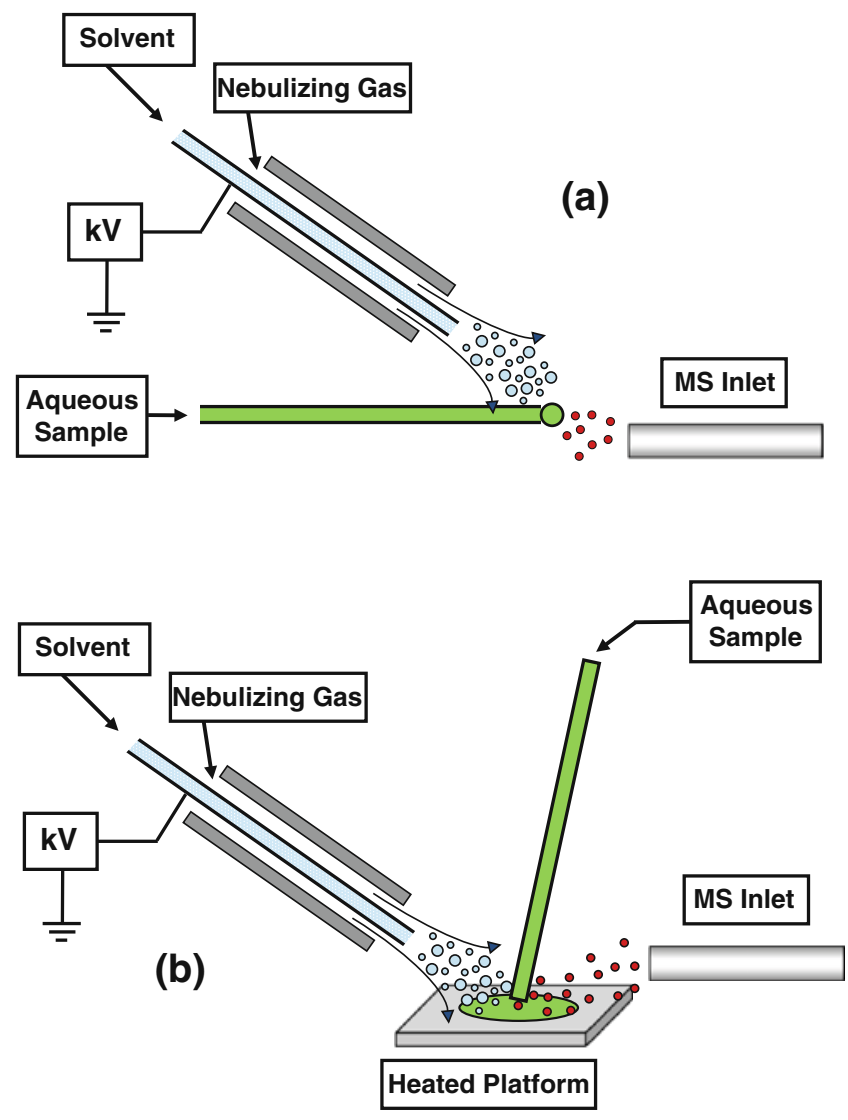

Figure 1. Ionization source designs for direct analysis of aqueous samples. (a) For direct flow injection DESI-MS (Method 1), the sample delivery capillary egress serves as the DESI analysis point. (b) For thermally-assisted DESI-MS (Method 2), aqueous sample is deposited onto a heated platform, which serves as the DESI analysis point 
(Hamilton Co., Reno, NV, USA) controlled by a syringe pump (Harvard Apparatus, Holliston, MA, USA). This sample delivery capillary was mounted to a glass slide, allowing it to be accurately positioned in respect to the electrospray emitter and atmospheric inlet of the MS instrument. Optimal ion intensities were obtained using a delivery capillary to MS inlet distance of $2 \mathrm{~mm}$, with the delivery capillary positioned $0.5 \mathrm{~mm}$ above axis in regards to the MS inlet. Electrospray emitter positioning was similar to that previously reported [12], using an incident angle of $40^{\circ}$ and emitter-to-sample distance of $5 \mathrm{~mm}$. The DESI spray solvent (1:1 methanol:water with $1 \%$ formic acid) flow rate was $1.5 \mu \mathrm{L} / \mathrm{min}$, and the aqueous sample flow rate was $2.0 \mu \mathrm{L} / \mathrm{min}$. For experiments utilizing Method 1, the end of the sample delivery capillary served as the DESI-MS analysis point.

\section{Method 2. Thermally-Assisted DESI-MS}

To evaluate the effect of thermal assistance on DESI-MS analysis of aqueous samples, a fused-silica capillary was used to introduce aqueous samples (similar to Method 1) directly onto a heated surface, with this surface serving as the DESI-MS analysis point (Figure 1b). A glass slide printed with PTFE wells (Prosolia) was used as the surface, and heat was applied directly to this slide via an Omegalux rope heater (Omega Engineering, Inc., Stamford, CT, USA) controlled by a variable transformer (Staco Energy Products Co., Dayton, OH, USA). The sampling surface was maintained at $\sim 220{ }^{\circ} \mathrm{C}$, using an infrared thermometer (Omega) for temperature measurement. The sample delivery capillary continuously infused aqueous analyte to a single PTFE well positioned $2 \mathrm{~mm}$ from the MS inlet. The electrospray emitter was focused onto this PTFE well, with positioning similar to Method 1, allowing immediate analysis of the infused aqueous sample. The DESI spray solvent (1:1 methanol:water with $1 \%$ formic acid) flow rate was $1.5 \mu \mathrm{L} / \mathrm{min}$, and the aqueous sample flow rate was varied between 1.0 to $90 \mu \mathrm{L} / \mathrm{min}$ for experimental purposes.

\section{Sample Preparation}

For evaluation of Method 1, aqueous solutions containing dissolved pharmaceutical tablets were investigated. Common over-the-counter (OTC) pharmaceutical tablets, including Benadryl (diphenhydramine), Imodium A-D (loperamide), Claritin (loratadine), Sudafed Congestion (pseudoephedrine), and Sudafed PE Sinus and Allergy (chlorpheniramine and phenylephrine) were purchased from local retail stores. Stock solutions were prepared by crushing tablets using a mortar and pestle, dissolving in methanol, and centrifuging to remove any insoluble binders. Aqueous samples were prepared from the stock solutions via serial dilutions in deionized water without further purification.
For evaluation of Method 2, standard solutions of prescription antidepressants (amitriptyline, bupropion, citalopram, clomipramine, duloxetine, fluoxetine, nortriptyline, paroxetine, sertraline, venlafaxine), $\beta_{1}$ receptor antagonists (antenolol), OTC antihistamines (diphenhydramine, chlorpheniramine), OTC analgesics (acetaminophen), anticonvulsants (carbamazepine), antibacterials (moxifloxacin), steroid hormones (estradiol), and caffeine were purchased from Cerilliant Corp. (Round Rock, TX, USA), while the antimicrobial agent triclosan and the insect repellant $N, N$ diethyl- $m$-toluamide (DEET) were purchased as standard solutions from AccuStandard, Inc. (New Haven, CT, USA). Aqueous samples were prepared from the stock solutions via serial dilutions in either deionized water or tap water (Normal, IL, conductivity measured to be $550 \mu \mathrm{S} / \mathrm{cm}$ ) without further purification.

\section{Results and Discussion}

An array of PPCPs contaminants was analyzed in this study, and structures and spectra for those that are not formally reported here can be found in the Supplementary Material, with special interest given to analytes not previously reported with DESI-MS.

\section{Direct Flow Injection DESI-MS of PPCPS}

Representative data was obtained with Method 1 from aqueous solutions containing common antihistamines (diphenhydramine, loratadine, chlorpheniramine), decongestants (phenylephrine, pseudoephedrine), and the antidiarrheal loperamide. The high usage and ease of acquisition of these pharmaceuticals make them an increased risk of contamination, by both natural excretion and improper disposal. Chemical structures and tablet information can be found is Table S-1.

Figure $2 \mathrm{a}$ shows a positive ion DESI mass spectrum using Method 1 for $\sim 2$ parts per million (ppm) loperamide in deionized water. Loperamide, a synthetic derivative of piperadine, acts as an opiod-receptor agonist and is commonly used in antidiarrheal medications. Aqueous sample was infused at a rate of $2.0 \mu \mathrm{L} / \mathrm{min}$, with the exit of the sample delivery capillary serving as the DESI analysis point. Mass spectra indicating the presence of loperamide were obtained rapidly, and less than $10 \mu \mathrm{L}$ of total sample was needed to obtain results. In Figure 2a, the presence of loperamide ( $\mathrm{MW}=477.037 \mathrm{~g} / \mathrm{mol}$ ) is confirmed by the protonated molecule $[\mathrm{M}+\mathrm{H}]^{+}$, seen as a doublet at $\mathrm{m} / \mathrm{z} 477$ and 479 due to the characteristic chlorine isotopic signature. Further confirmation is gained by tandem MS $\left(\mathrm{MS}^{2}\right)$ analysis, as seen in Figure 2b, which yields characteristic fragment ions at $\mathrm{m} / \mathrm{z} 210,266$, and 459 , corresponding to a losses of $N, N$-dimethyl-2,2diphenylbutanamide, 4-( $p$-chlorophenyl)-4-hydroxypiperidine and water, respectively, similar to losses reported in ESI-MS literature [31]. 

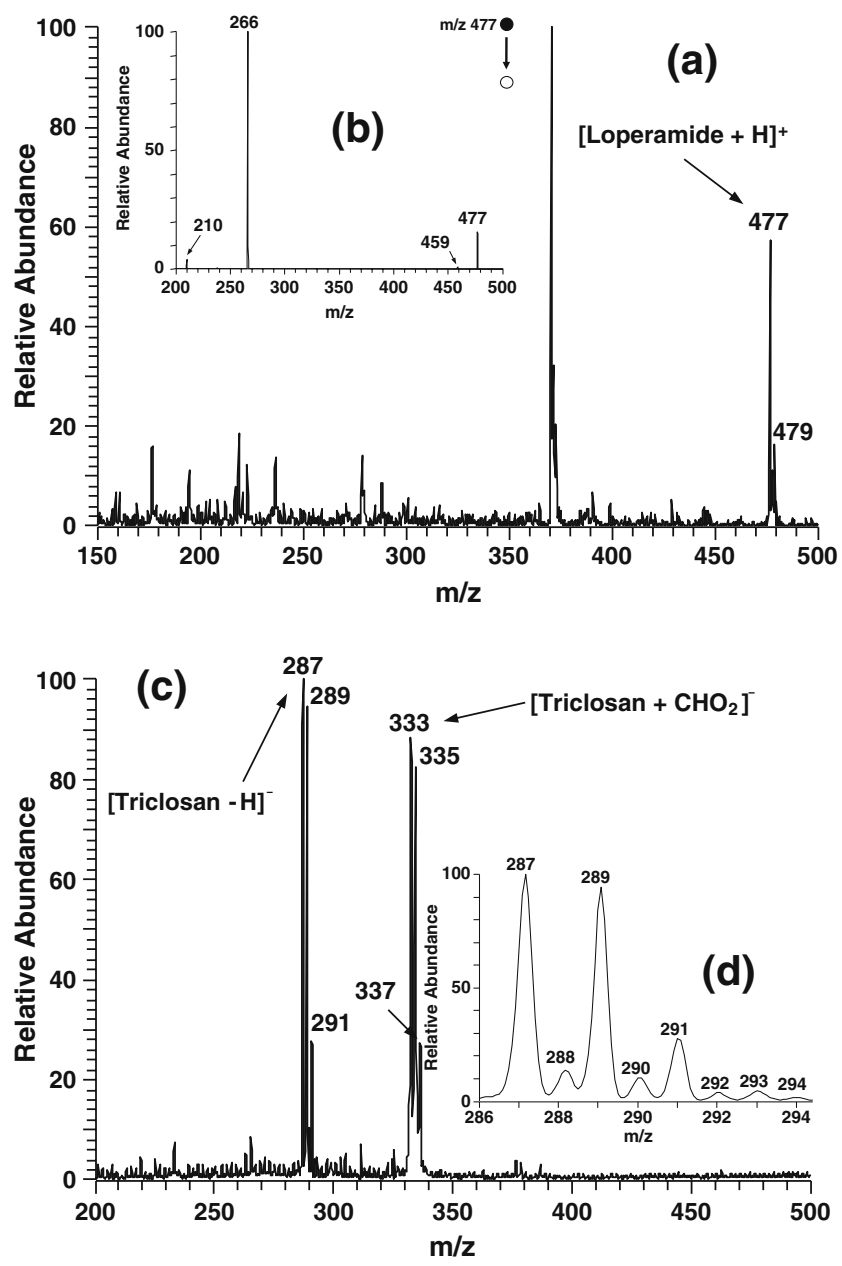

Figure 2. (a) Positive ion DESI mass spectrum using Method 1 for $\sim 2$ ppm loperamide in deionized water. The protonated molecule shows the characteristic chlorine isotopic signature at $\mathrm{m} / \mathrm{z} 477$ and 479 . (b) $\mathrm{MS}^{2}$ of the $\mathrm{m} / \mathrm{z} 477$ precursor ion, yielding characteristic fragment ions at $\mathrm{m} / \mathrm{z}$ 210, 266, and 459, corresponding to a losses of $N, N$ dimethyl-2,2-diphenylbutanamide, 4-( $p$-chlorophenyl)-4hydroxypiperidine and water, respectively. (c) Negative ion DESI mass spectrum using Method 2 for 100 ppb triclosan in deionized water. The deprotonated molecule is a seen as a peak envelope from $\mathrm{m} / \mathrm{z} 287$ to 294, with a characteristic trichlorinated isotopic distribution, and a formate adduct, $\left[\mathrm{M}+\mathrm{CHO}_{2}\right]^{-}$, can be seen from $\mathrm{m} / \mathrm{z} 333$ to 340 . (d) Experimental isotopic abundances coincide well with theoretical yields for the trichlorinated aromatic compound

Utilizing direct flow injection DESI-MS, typical limits of detection ranged from 10 to 100 parts per billion ( $\mathrm{ppb}$ ) for the target analytes using single reaction monitoring (SRM) scan modes, with representative data being found in Figures S-1 to S-6. While these detection limits are lower than those previously reported for similar analyses [23], typical concentrations of PPCPs in environmental samples can range from low $\mathrm{ppb}$ in untreated sources like sewage effluent [32] to low or sub-ppt in processed water supplies and aquatic environments [11]. To allow trace analysis of unprepared aqueous samples with direct flow injection DESI-MS, detection limits would have to be reduced without prior preconcentration.

\section{Thermally-Assisted DESI-MS of PPCPS}

Building upon the results obtained for Method 1, decreased detection limits for infused aqueous samples were obtained by deposition onto a heated surface, with this surface serving as the DESI-MS analysis point (Method 2). Representative data obtained with Method 2 from aqueous solutions containing triclosan, chlorpheniramine, and citalopram can be found in Figures 2, S-8, and S-9, respectively, and chemical structures (Table S-2) and a mass spectral library of other target PPCPs can be found in the Supplementary Material.

Triclosan was selected as a target analyte due to its common use in antibacterial hygiene products, including soaps, shampoos, deodorants, lotions, and toothpaste, and emergence as a persistent contaminant in natural waters. The Federal Food and Drug Administration (FDA) is currently reviewing this bactericide due to concerns that repetitive daily exposure could cause endocrine disruption [33], making it a contaminant of increased interest. Figure 2c shows a negative ion DESI mass spectrum using Method 2 for $100 \mathrm{ppb}$ triclosan in tap water. As a trichlorinated aromatic compound, triclosan is seen as a characteristic envelope of peaks from $\mathrm{m} / \mathrm{z} 287$ to 294 , corresponding to the deprotonated molecule, and experimental isotopic abundances coincided well with theoretical yields (Figure 2d). The mass spectrum also shows a similar isotopic distribution from $\mathrm{m} / \mathrm{z} 333$ to 340 , corresponding to formate adduct formation, $\left[\mathrm{M}+\mathrm{CHO}_{2}\right]^{-}$, which has been seen in atmospheric pressure chemical ionization (APCI-MS) analysis of aromatic explosives under similar solvent conditions [34]. The DESI spray solvent utilized for the entire series of analyses was 1:1 methanol:water with $1 \%$ formic acid, and while adjusting the solvent system can provide better sensitivity on a per compound basis, a single system was used to simplify the overall method. The presence of formate in the spray solvent leads to this characteristic adduct, adding additional selectivity to the analysis of triclosan. Adding reactive species to the spray solvent has been termed reactive DESI-MS [15, 35], and maintaining this ability with Method 2 allows flexibility in analyzing future contaminants of interest.

Representative spectra obtained for analysis of $100 \mathrm{ppb}$ aqueous solutions of chlorpheniramine can be seen Figure S-8a. Chlorpheniramine, a histamine receptor antagonist, is commonly incorporated individually or in conjunction with decongestants in pharmaceutical compositions. Positive ion DESI analysis utilizing Method 2 yielded the protonated molecule for chlorpheniramine with a chlorine isotopic distribution at $\mathrm{m} / \mathrm{z} 275$ and 277. Figure S-8b shows the $\mathrm{MS}^{2}$ spectrum of the $\mathrm{m} / \mathrm{z} 275$ precursor ion (corresponding to 
the ${ }^{35} \mathrm{Cl}$ isotope), which dissociates by loss of ethylamine to produce an ion of $\mathrm{m} / \mathrm{z} 230$.

Figure S-9a shows a positive ion DESI mass spectrum using Method 2 for $100 \mathrm{ppb}$ citalopram in tap water. Citalopram is in the selective serotonin reuptake inhibitor (SSRI) class of antidepressants, and is marketed as the product Celexa. Citalopram is seen as the protonated molecule at $\mathrm{m} / \mathrm{z}$ 325. Fragmentation of the $\mathrm{m} / \mathrm{z} 325$ precursor yields several product ions, as seen in Figure $\mathrm{S}-9 \mathrm{~b}$, with the main product at $\mathrm{m} / \mathrm{z} 262$ corresponding to a loss of 2-fluoro-ethylamine.

\section{Complex Mixture Analysis}

Since real environmental samples can vary in terms of chemical complexity, the robustness of Method 2 to multicomponent sample analysis was demonstrated. Figure 3 shows a positive ion DESI mass spectrum of tap water spiked with $1 \mathrm{ppb}$ each of DEET ( $\mathrm{m} / \mathrm{z} 192)$, caffeine $(\mathrm{m} / \mathrm{z}$ 195), carbamazepine $(\mathrm{m} / \mathrm{z} 237)$, diphenhydramine $(\mathrm{m} / \mathrm{z} 256)$, chlorpheniramine ( $\mathrm{m} / \mathrm{z} 275$ and 277), and citalopram $(\mathrm{m} / \mathrm{z}$ 325), all confirmed by tandem MS analysis. Even at a relatively low concentration, analytes of interest can still be discerned from the noise level in the full scan mass spectrum, showing the sensitivity of thermally-assisted DESI-MS for aqueous PPCP analysis. The variance among peak intensities is indicative of differing ionization efficiencies, but also could be the result of charge competition amongst the analytes [36].

\section{Sensitivity Enhancements and Detection Limits from Thermal Assistance}

To assess how the thermal assistance afforded by Method 2 affected sensitivity of analysis, ion intensities were examined for both chlorpheniramine and citalopram with and without heat applied to the deposition surface. For comparison purposes, integrated peak areas for the major transition were obtained via SRM scan mode for both analytes at a concentration of $1 \mathrm{ppb}$, and the average of three separate experimental runs was calculated. Applying thermal assistance to the deposition surface resulted in signal enhancements of 1.54 and 1.60 orders of magnitude for chlorpheniramine and citalopram, respectively, correlating to $\sim 1.5$ orders of magnitude lower detection limits for these compounds by simply heating the surface serving as the DESI analysis point to $220{ }^{\circ} \mathrm{C}$.

A systematic study of the sensitivity enhancement from thermal assistance can be seen in Figure 4a, where the signal intensity of the major SRM transition of chlorpheniramine $(\mathrm{m} / \mathrm{z} 230$, loss of ethylamine) was monitored as a function of deposition surface temperature. The temperature range investigated extended from room temperature $\left(25^{\circ} \mathrm{C}\right)$ to a maximum of $220^{\circ} \mathrm{C}$. As seen, an increase in signal intensity was immediately gained upon raising the deposition surface temperature, with the most pronounced increase beginning around $175^{\circ} \mathrm{C}$. This steep increase extends to the maximum temperature investigated. Higher temperatures were investigated, but $220{ }^{\circ} \mathrm{C}$ was optimal for thermal assistance, as significant boiling of the infused aqueous sample was seen after this temperature and the PTFE used as the deposition/ analysis surface undergoes thermal degradation at $260{ }^{\circ} \mathrm{C}$.

Table 1 provides a summary of limit of detection (LOD) studies for select PPCP in tap water matrices performed with Method 2, including major SRM transitions and associated fragmentation. DESI-MS analyses of infused aqueous PPCP contaminants routinely gave low ppt detection limits when incorporating thermal assistance. All reported detection limits were experimentally obtained, utilizing the traditional LOD threshold of 3 for the signal-to-noise ratio. Detection limit studies for triclosan were accomplished in full scan mode, as the major product ion for this contaminant is ${ }^{35} \mathrm{Cl}^{-}$, which lies below the low mass cutoff of the mass spectrometer utilized. In full scan mode, the LOD of triclosan was $30 \mathrm{ppb}$, a bit higher than full scan mode LODs obtained for other PPCPs analyzed (typically $1-10 \mathrm{ppb}$ ), but a

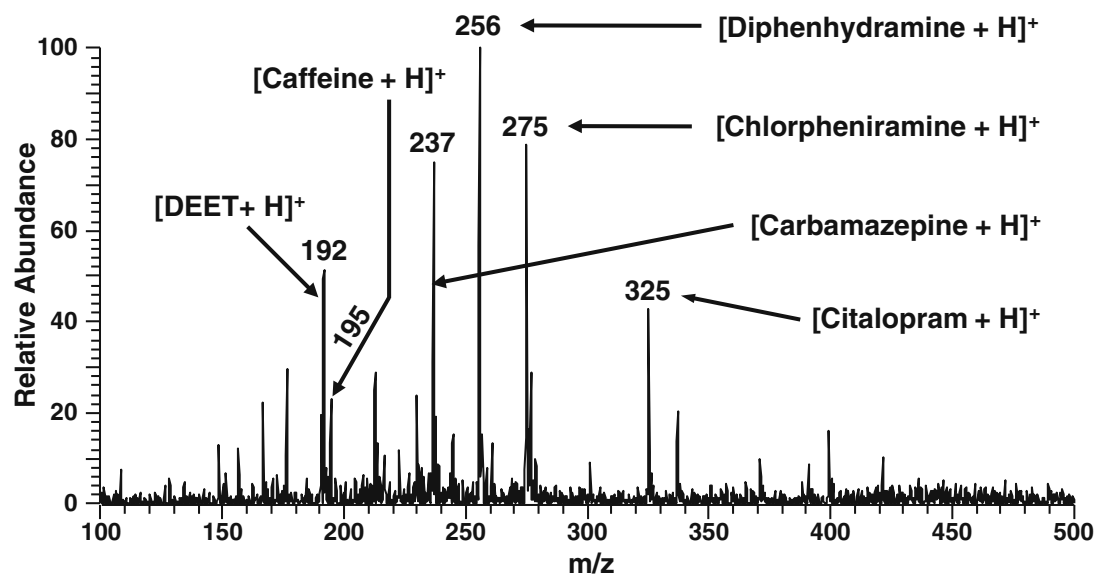

Figure 3. Positive ion DESI mass spectrum of tap water spiked with 1 ppb each of DEET $(\mathrm{m} / z$ 192), caffeine $(\mathrm{m} / \mathrm{z} 195)$, carbamazepine $(\mathrm{m} / \mathrm{z} 237)$, diphenhydramine $(\mathrm{m} / \mathrm{z} 256)$, chlorpheniramine $(\mathrm{m} / \mathrm{z} 275$ and 277), and citalopram $(\mathrm{m} / \mathrm{z} 325)$, all confirmed by tandem MS analysis 

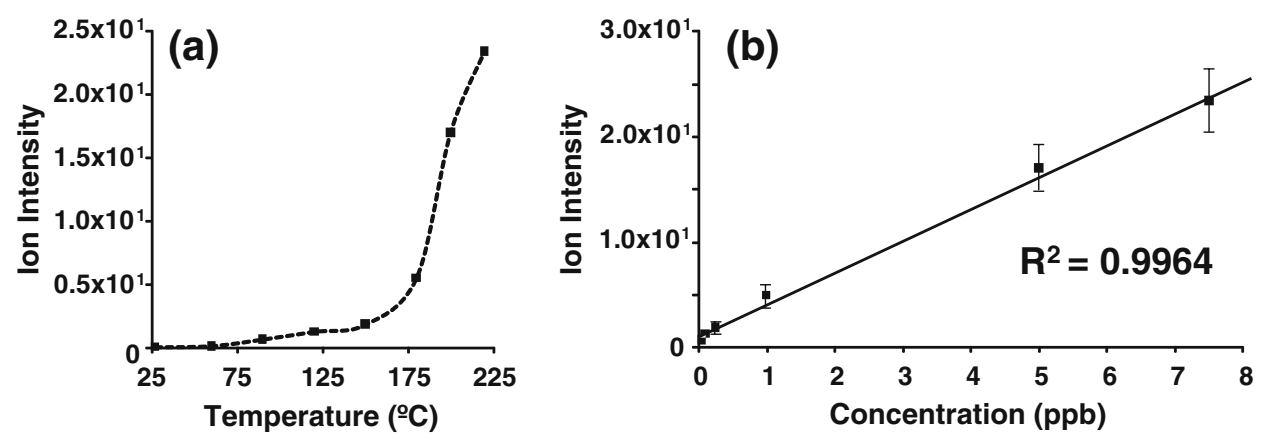

Flow Rate ( $\mu \mathrm{L} / \mathrm{min})$

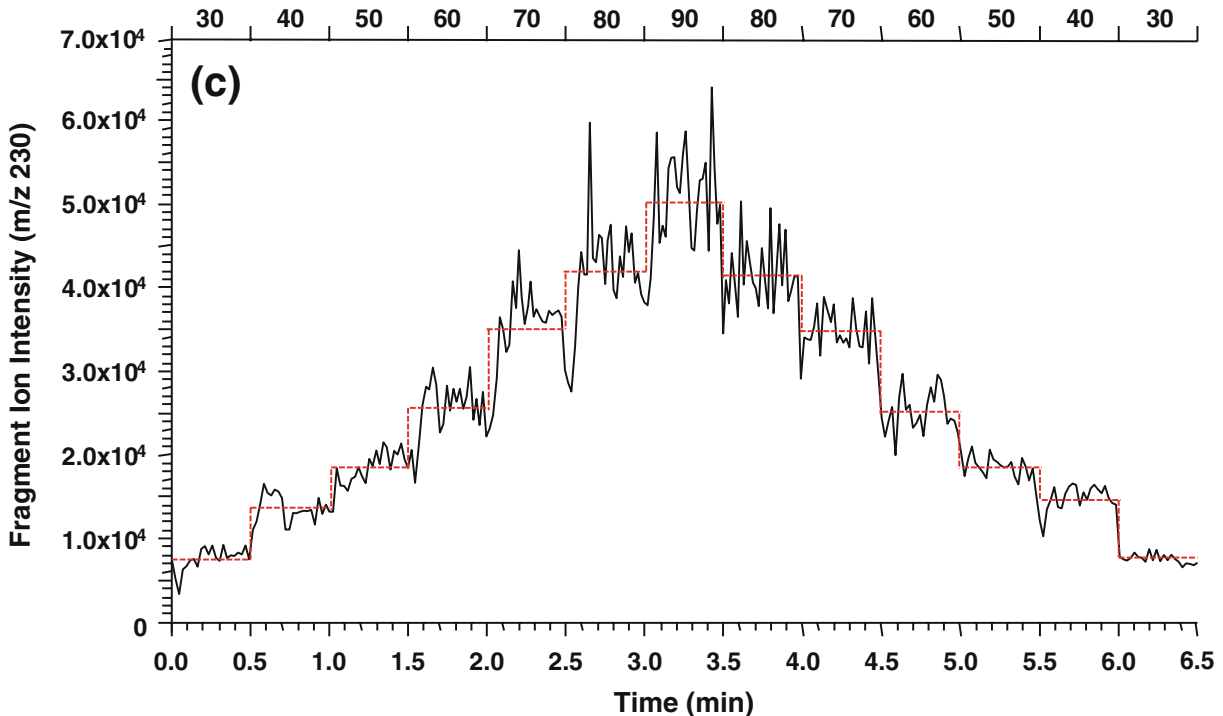

Figure 4. Characterization of thermally-assisted DESI-MS for aqueous PPCP analysis. (a) Effect of deposition surface temperature on the signal intensity of the SRM transition of chlorpheniramine. (b) Calibration curve generated from aqueous solutions of citalopram, ranging from the limit of quantitation of 20 to $7500 \mathrm{ppt}$. The correlation coefficient resulting from these analyses was 0.9964 , and relative standard deviations for all calibration points ranged from 6 to $13 \%$, showing decent precision and linearity for the entire quantitation experiment. (c) lon chromatogram for the major transition of chlorpheniramine measured as a function of flow rate of infused sample. Intensities for specific flow rates during the increasing ( 0.0 to 3.0 min) and decreasing (3.5 $\mathrm{min}$ to $6.5 \mathrm{~min}$ ) time intervals are congruent, showing a resistance to carryover effects at moderate concentrations

Table 1. Major SRM Transitions and Detection Limits for Select PPCPs Spiked in Tap Water

\begin{tabular}{|c|c|c|c|}
\hline Compound & Precursor ion $(\mathrm{m} / \mathrm{z})$ & SRM Transition $(m / z)$ & LOD (ppt) \\
\hline \multicolumn{4}{|l|}{ Antidepressants } \\
\hline Bupropion & $240[\mathrm{M}+\mathrm{H}]^{+}$ & $184\left[\mathrm{M}-\mathrm{C}_{4} \mathrm{H}_{8}+\mathrm{H}\right]^{+}$ & 10 \\
\hline Citalopram & $325[\mathrm{M}+\mathrm{H}]^{+}$ & $262\left[\mathrm{M}-\mathrm{C}_{2} \mathrm{H}_{6} \mathrm{NF}+\mathrm{H}\right]^{+}$ & 9.0 \\
\hline Venlafaxine & $278[\mathrm{M}-\mathrm{H}]^{+}$ & $260\left[\mathrm{M}-\mathrm{H}_{2} \mathrm{O}+\mathrm{H}\right]^{+}$ & 25 \\
\hline \multicolumn{4}{|l|}{ Antihistamines } \\
\hline Chlorpheniramine & $275[\mathrm{M}+\mathrm{H}]^{+}$ & $230\left[\mathrm{M}-\mathrm{C}_{2} \mathrm{H}_{7} \mathrm{~N}+\mathrm{H}\right]^{+}$ & 18 \\
\hline Diphenhydramine & $256[\mathrm{M}+\mathrm{H}]^{+}$ & $167\left[\mathrm{M}-\mathrm{C}_{4} \mathrm{H}_{11} \mathrm{NO}+\mathrm{H}\right]^{+}$ & 76 \\
\hline \multicolumn{4}{|l|}{ Analgesics } \\
\hline Acetaminophen & $152[\mathrm{M}+\mathrm{H}]^{+}$ & $110\left[\mathrm{M}-\mathrm{CH}_{2}-\mathrm{CO}+\mathrm{H}\right]^{+}$ & 23 \\
\hline \multicolumn{4}{|l|}{ Anticonvulsant } \\
\hline Carbamazepine & $237[\mathrm{M}+\mathrm{H}]^{+}$ & $194[\mathrm{M}-\mathrm{CHNO}+\mathrm{H}]^{+}$ & 0.90 \\
\hline \multicolumn{4}{|c|}{ Personal care products } \\
\hline DEET & $192[\mathrm{M}+\mathrm{H}]^{+}$ & $119\left[\mathrm{M}-\mathrm{C}_{4} \mathrm{H}_{11} \mathrm{~N}+\mathrm{H}\right]^{+}$ & 8.0 \\
\hline Caffeine & $195[\mathrm{M}+\mathrm{H}]^{+}$ & $138\left[\mathrm{M}-\mathrm{C}_{2} \mathrm{H}_{3} \mathrm{NO}+\mathrm{H}\right]^{+}$ & 43 \\
\hline \multirow[t]{2}{*}{ Triclosan } & $287[\mathrm{M}-\mathrm{H}]^{-}$ & N/A* & \\
\hline & $333\left[\mathrm{M}+\mathrm{CHO}_{2}\right]^{-}$ & & \\
\hline
\end{tabular}

*Not applicable. Major product ion $\left({ }^{35} \mathrm{Cl}^{-}\right)$below low mass cutoff of Thermo LCQ Fleet 
significant amount of ion intensity is distributed among the isotopic ions, as well as those for the formate adduct (Figure 2c). Of note, sub-ppt detection limits were obtained for the anticonvulsant carbamazepine, which yielded a LOD of 900 parts per quadrillion (ppq). While this result represents the lowest LOD obtained for the selected PPCPs, breaking the ppq threshold is a notable achievement, as this is similar performance of hyphenated mass spectrometric methods that utilized extensive sample preparation and preconcentration. The low ppt detection limits afforded by this methodology are approaching relevant concentration ranges for aqueous contaminant monitoring and toxicologic assessments.

The sensitivity enhancement realized from thermal assistance in these studies is impressive, and there are several potential explanations for this increase in sensitivity. As aqueous sample is infused onto the heated platform, it quickly increases in temperature. This could lead to evaporation of water in the sample, increasing the concentration of analyte in the progeny droplets leaving the surface as result of the "droplet pickup" desorption mechanism of DESI-MS [37]. The progeny droplets leaving the surface will also have a higher temperature, further assisting solvent evaporation and allowing the Rayleigh limit of the droplet to be attained rapidly [38]; this could lead to a larger population of gas-phase analyte ions being generated before entrance into the heated MS inlet. As simulated by Costa and Cooks [37], the size of the desorbed droplets has a dramatic effect on the angle of departure from the surface, and smaller droplets have a low altitude trajectory, gliding just above the sample surface. If incorporating thermal assistance was affecting the size of generated droplets that leave the heated surface, this could lead to preferential generation of small droplets, and depending on the source alignment in respect to the MS inlet, could lead to higher efficiency collection of analyte ions and sensitivity.

\section{Quantitation and Optimization of Sample Flow Rate}

While rapid monitoring of aqueous PPCP contaminants is of high interest to environmental protection, the ability to quantify these species is necessary in assessing remediation efforts [4] and establishing geographical and temporal trends of contaminant plumes [39]. Figure $4 \mathrm{~b}$ shows a calibration curve generated from tap water solutions of citalopram, ranging from the limit of quantitation (LOQ) of $20 \mathrm{ppt}$ to 7500 ppt. For comparison purposes, integrated peak areas for the major transition $(\mathrm{m} / \mathrm{z} 262$, loss of 2-fluoro-ethylamine) were obtained via SRM scan mode, and the average of three separate experimental runs was calculated. The correlation coefficient $\left(\mathrm{R}^{2}\right)$ resulting from these analyses was 0.9964 , and relative standard deviations for all calibration points ranged from $6 \%$ to $13 \%$, showing decent precision and linearity for the entire quantitation experiment. Of note, the precision and linearity using Method 2 is comparable to quantitative DESI-MS analyses reported that utilize internal standards and automated positioning systems [40]. The linear dynamic range (LDR) for quantitation of citalopram was approaching three orders of magnitude without utilizing software-controlled automatic gain control (AGC). Implementing AGC into quantitative experiments could yield larger ranges of linearity for concentrated sample analysis.

While these quantitative results involving lab-generated samples are promising, this methodology will have to be shown applicable to other authentic sample matrices, as sewage effluent, ground, and surface water samples will have varying chemical complexity, salt concentration, $\mathrm{pH}$ and particulate matter. Systematic studies of how and to what magnitude these matrix constituents reduce the ionization efficiency of aqueous contaminants and effect quantitation will need to be undertaken in order to develop methods to reduce ion suppression, though recent studies suggest that DESI-MS is more tolerant to salt concentration than traditional ESI methods [41].

For thermally-assisted DESI-MS of infused aqueous samples, sample flow rates were seen to have a dramatic effect on analyte ion intensity. Optimization of sample flow rates was accomplished by monitoring the peak height for the major transition via SRM scan mode of a $100 \mathrm{ppb}$ aqueous solution of chlorpheniramine over a range of 1.0 to $120 \mu \mathrm{L} / \mathrm{min}$. Ion intensity increased linearly with flow rate over this range, and $90 \mu \mathrm{L} / \mathrm{min}$ was determined to optimal, as it provided the highest intensity while being resistant to pooling of aqueous sample on the deposition surface. Flow rates higher than $90 \mu \mathrm{L} / \mathrm{min}$ overcame solvent evaporation from thermal assistance and sample removal via the desorption mechanism of DESI-MS [42], causing pooling of sample by the MS atmospheric inlet. Pooling of sample on the deposition surface could lead to carryover effects, but more importantly, allowing condensed phases like water to enter the atmospheric inlet could be detrimental to the MS vacuum system. When utilizing a sample flow rate of $90 \mu \mathrm{L} / \mathrm{min}$ and a deposition surface temperature of $220^{\circ} \mathrm{C}$, mass spectral data can be collected in $\sim 1 \mathrm{~min}$, leading to a total sample consumption of less than $100 \mu \mathrm{L}$.

Figure $4 \mathrm{c}$ shows an ion chromatogram for the major transition of chlorpheniramine $(\mathrm{m} / \mathrm{z} 230$, as seen in Figure $\mathrm{S}-8 \mathrm{~b}$ ) measured as a function of flow rate of infused sample. Flow rates were incrementally increased by $10 \mu \mathrm{L} / \mathrm{min}$ at $0.5 \mathrm{~min}$ intervals from 30 to $90 \mu \mathrm{L} / \mathrm{min}$ and then decreased using similar syringe pump settings back to $30 \mu \mathrm{L} / \mathrm{min}$. For this analysis, the DESI-MS analysis point and concentration of aqueous analyte were held constant. At the beginning of each time interval, the chromatogram slightly declines, an artifact due to the syringe pump adjusting to the new flow rate that could be reduced by using a pulse dampener. For each time interval, RSDs were calculated for the respective data, including the artifact due to syringe pumping. Interval RSDs ranged from $5.0 \%$ to $18 \%$, and the average RSD over all intervals was $8.3 \%$. The average intensity of $\mathrm{m} / \mathrm{z} 230$ was calculated for the respective data of each interval and plotted 
as the step-wise, dotted line overlay (shown in red). Of note, intensities for specific flow rates during the increasing $(0.0$ to $3.0 \mathrm{~min}$ ) and decreasing $(3.5 \mathrm{~min}$ to $6.5 \mathrm{~min}$ ) time intervals are congruent, demonstrating the reproducibility of the technique, but more importantly, showing a resistance to carryover effects at moderate concentrations.

\section{Conclusions}

A variant of DESI-MS has been developed that allows rapid, dynamic analysis of unprepared contaminated water samples, characterizing the technique through analysis of common PPCP contaminants in tap water matrices. By incorporating thermal assistance, low ppt detection limits were routinely obtained for PPCP contaminants in tap water matrices, realizing a sensitivity increase approaching two orders of magnitude. Besides allowing rapid, direct analysis and quantitation of unprepared water samples, this methodology also has low sample volume requirements, making it an attractive alternative to current chromatographic methods that require large volumes to be shipped from sampling sites to off-site laboratories. Similar to traditional DESI-MS [12], intensity of analysis is dependent on optimal positioning of the electrospray emitter, analysis surface, and atmospheric inlet of the mass spectrometer. As with any analysis involving heating of analyte, thermally-labile compounds could exhibit fragmentation in precursor MS scans, increasing spectral complexity. Coupled with field-portable mass spectrometric instrumentation [43-45], this methodology could be used as a stand-alone sensor in long-term monitoring programs and remediation efforts, allowing the determination of new contaminants and detection of degradation and metabolic products of those already established.

\section{Acknowledgments}

The authors acknowledge funding from the Research Corporation for Scientific Advancement Cottrell College Science Award (RCSA-CCSA) Program and Illinois State University.

\section{References}

1. Daughton, C.G., Ternes, T.A.: Pharmaceuticals and personal care products in the environment: agents of subtle change? Environ. Health Perspect. 107(Suppl. 6), 907-938 (1999)

2. Daughton, C.G.: Emerging pollutants, and communicating the science of environmental chemistry and mass spectrometry: pharmaceuticals in the environment. J. Am. Soc. Mass Spectrom. 12, 1067-1076 (2001)

3. Ellis, J.B.: Pharmaceuticals and personal care products (PPCPs) in urban receiving waters. Environ. Pollut. 114, 184-189 (2006)

4. Stackelberg, P.E., Gibs, J., Furlong, E.T., Meyer, M.T., Zaugg, S.D., Lippincott, R.L.: Efficiency of conventional drinking-water-treatment processes in removal of pharmaceuticals and other organic compounds. Sci. Total Environ. 377, 255-272 (2007)

5. Kosjek, T., Heath, E., Petrović, M., Barceló, D.: Mass spectrometry for identifying pharmaceutical biotransformation products in the environment. TrAC Trends Anal Chem 26, 1076-1085 (2007)
6. Onesios, K., Yu, J., Bouwer, E.J.: Biodegradation and removal of pharmaceuticals and personal care products in treatment systems: a review. Biodegradation 20, 441-466 (2009)

7. Pérez, S., Barceló, D.: Applications of LC-MS to quantitation and evaluation of the environmental fate of Chiral drugs and their metabolites. TrAC Trends Anal Chem 27, 836-846 (2008)

8. Buchberger, W.W.: Current approaches to trace analysis of pharmaceuticals and personal care products in the environment. J. Chromatogr. A 1218, 603-618 (2010)

9. Richardson, S.D.: Environmental mass spectrometry: emerging contaminants and current issues. Anal. Chem. 82, 4742-4774 (2010)

10. Kostopoulou, M., Nikolaou, A.: Analytical problems and the need for sample preparation in the determination of pharmaceuticals and their metabolites in aqueous environmental matrices. TrAC Trends Anal Chem 27, 1023-1035 (2008)

11. la Farré, M., Pérez, S., Kantiani, L., Barceló, D.: Fate and toxicity of emerging pollutants, their metabolites, and transformation products in the aquatic environment. TrAC Trends Anal Chem 27, 991-1007 (2008)

12. Cooks, R.G., Ouyang, Z., Takáts, Z., Wiseman, J.M.: Ambient mass spectrometry. Science 311, 1566-1577 (2006)

13. Chen, H.W., Gamez, G., Zenobi, R.: What can we learn from ambient ionization techniques? J. Am. Soc. Mass Spectrom. 20, 1947-1963 (2009)

14. Weston, D.J., Bateman, R., Wilson, I.D., Wood, T.R., Creaser, C.S.: Direct analysis of pharmaceutical drug formulations using ion mobility spectrometry/quadrupole-time-of-flight mass spectrometry combined with desorption electrospray ionization. Anal. Chem. 77, 7752-7580 (2005)

15. Nyadong, L., Green, M.D., De Jesus, V.R., Newton, P.N., Fernandez, F. M.: Reactive desorption electrospray ionization linear ion trap mass spectrometry of latest-generation counterfeit antimalarials via noncovalent complex formation. Anal. Chem. 79, 2150-2157 (2007)

16. Cotte-Rodríguez, I., Mulligan, C.C., Cooks, R.G.: Non-proximate detection of small and large molecules by desorption electrospray ionization and desorption atmospheric pressure chemical ionization mass spectrometry: instrumentation and applications in forensics, chemistry, and biology. Anal. Chem. 79, 7069-7077 (2007)

17. Cody, R.B., Laramee, J.A., Durst, H.D.: Versatile new ion source for the analysis of materials in open air under ambient conditions. Anal. Chem. 77, 2297-2302 (2005)

18. Petucci, C., Diffendal, J., Kaufman, D., Mekonnen, B., Terefenko, G., Musselman, B.: Direct analysis in real time for reaction monitoring in drug discovery. Anal. Chem. 79, 5064-5070 (2007)

19. Huang, M.Z., Hsu, H.J., Wu, C.I., Lin, S.Y., Ma, Y.L., Cheng, T.L., Shiea, J.: Characterization of the chemical components on the surface of different solids with electrospray-assisted laser desorption ionization mass spectrometry. Rapid Commun. Mass Spectrom. 21, 1767-1775 (2007)

20. Harper, J.D., Charipar, N.A., Mulligan, C.C., Zhang, X., Cooks, R.G., Ouyang, Z.: Low-temperature plasma probe for ambient desorption ionization. Anal. Chem. 80, 9097-9104 (2008)

21. Chipuk, J.E., Brodbelt, J.S.: Transmission mode desorption electrospray ionization. J. Am. Soc. Mass Spectrom. 19, 161-1620 (2008)

22. Ma, X., Zhao, M., Lin, Z., Zhang, S., Yang, C., Zhang, X.: Versatile platform employing desorption electrospray ionization mass spectrometry for high-throughput analysis. Anal. Chem. 80, 6131-6138 (2008)

23. Miao, Z., Chen, H.: Direct analysis of liquid samples by desorption electrospray ionization-mass spectrometry (DESI-MS). J. Am. Soc. Mass Spectrom. 20, 10-19 (2009)

24. Miao, Z., Wu, S., Chen, H.: The study of protein conformation in solution via direct sampling by desorption electrospray ionization mass spectrometry. J. Am. Soc. Mass Spectrom. 21, 1730-1736 (2010)

25. Luo, M., Hu, B., Zhang, X., Peng, D., Chen, H., Zhang, L., Huan, Y.: Extractive electrospray ionization mass spectrometry for sensitive detection of uranyl species in natural water samples. Anal. Chem. 82, 28-289 (2010)

26. Shiea, J., Yuan, C.H., Huang, M.Z., Cheng, S.C., Ma, Y.L., Tseng, W.L., Chang, H.C., Hung, W.C.: Detection of native protein ions in aqueous solution under ambient conditions by electrospray laser desorption/ ionization mass spectrometry. Anal. Chem. 80, 4845-4852 (2008)

27. Mulligan, C.C., MacMillan, D.K., Noll, R.J., Cooks, R.G.: Fast analysis of high-energy compounds and agricultural chemicals in water with desorption electrospray ionization mass spectrometry. Rapid Commun. Mass Spectrom. 21(22), 3729-3736 (2007)

28. Loftin, K.B., Griffin, T.P., Clausen, C.A., Cody R.B., Dane, A.J: A novel technique utilizing SBSE and DART-TOF for the analysis of 
pharmaceuticals and pesticide contaminants in aqueous media. Proceedings of the 57th Annual American Society for Mass Spectrometry Conference, Philadelphia, PA, June, 2009.

29. Fayad, P., Prévost, M., Sauvé, S.: Laser diode thermal desorption/ atmospheric pressure chemical ionization tandem mass spectrometry analysis of selected steroid hormones in wastewater: method optimization and application. Anal. Chem. 82, 639-645 (2010)

30. Nanita, S.C., Pentz, A.M., Bramble, F.Q.: High-throughput pesticide residue quantitative analysis achieved by tandem mass spectrometry with automated flow injection. Anal. Chem. 81, 3134-3142 (2009)

31. He, H., Sadeque, A., Erve, J.C., Wood, A.J.J., Hachey, D.L.: Quantitation of loperamide and $n$-demethyl-loperamide in human plasma using electrospray ionization with selected reaction ion monitoring liquid chromatography-mass spectrometry. J. Chromatogr. B Anal. Technol. Biomed. Life Sci. 744, 323-331 (2000)

32. Yu, J.T., Bouwer, E.J., Coelhan, M.: Occurrence and biodegradability studies of selected pharmaceuticals and personal care products in sewage effluent. Agric. Water Manag. 86, 72-80 (2006)

33. Federal Food and Drug Administration. Triclosan: What Consumers Should Know. http://www.fda.gov/forconsumers/consumerupdates/ ucm205999.htm. Accessed January 10, 2011.

34. Cassada, D.A., Monson, S.J., Snow, D.D., Spalding, R.F.: Sensitive determination of RDX, nitroso-RDX metabolites, and other munitions in ground water by solid-phase extraction and isotope dilution liquid chromatography-atmospheric pressure chemical ionization mass spectrometry. J. Chromatogr. A 844, 87-95 (1999)

35. Chen, H., Cotte-Rodríguez, I., Cooks, R.G.: cis-Diol functional group recognition by reactive desorption electrospray ionization (DESI). Chem. Comm. 597-599 (2006).
36. Tang, K., Page, J.S., Smith, R.D.: Charge competition and the linear dynamic range of detection in electrospray ionization mass spectrometry. J. Am. Soc. Mass Spectrom. 15, 1416-1423 (2004)

37. Costa, A.B., Cooks, R.G.: Simulation of atmospheric transport and droplet-thin film collisions in desorption electrospray ionization. Chem. Commun. 3915-3917 (2007).

38. Iribarne, J.V.: On the evaporation of small ions from charged droplets. J. Chem. Phys. 64, 2287-2294 (1976)

39. Zhu, L.Y., Hites, R.A.: Temporal trends and spatial distributions of brominated flame retardants in archived fishes from the great lakes. Environ. Sci. Technol. 38, 2779-2784 (2004)

40. Manicke, N.E., Kistler, T., Ifa, D.R., Cooks, R.G., Ouyang, Z.: Highthroughput quantitative analysis by desorption electrospray ionization mass spectrometry. J. Am. Soc. Mass Spectrom. 20, 321-325 (2009)

41. Jackson, A.U., Talaty, N., Cooks, R.G., Van Berkel, G.J.: Salt tolerance of desorption electrospray ionization (DESI). J. Am. Soc. Mass Spectrom. 18, 2218-2225 (2007)

42. Costa, A.B., Cooks, R.G.: Simulated splashes: elucidating the mechanism of desorption electrospray ionization mass spectrometry. Chem. Phys. Lett. 464, 1-8 (2008)

43. Mulligan, C.C., Talaty, N., Cooks, R.G.: Desorption electrospray ionization with a portable mass spectrometer: in-situ analysis of ambient surfaces. Chem. Commun. 1709-1711 (2006).

44. Wells, J.M., Roth, M.J., Keil, A.D., Grossenbacher, J.W., Justes, D.R., Patterson, G.E., Barket Jr., D.J.: Implementation of DART and DESI ionization on fieldable mass spectrometer. J. Am. Soc. Mass Spectrom. 19, 1419-1424 (2008)

45. Ouyang, Z., Noll, R.J., Cooks, R.G.: Handheld miniature ion trap mass spectrometers. Anal. Chem. 81, 2421-2425 (2009) 